\title{
Isolation by sugar flotation has no direct effect on the hatching success of zooplankton resting eggs
}

\author{
Dunja LUKIĆ,${ }^{1,2 *}$ Csaba F. VAD,${ }^{2}$ Zsófia HORVÁTH ${ }^{2}$ \\ ${ }^{1}$ Faculty of Biology, University of Belgrade, Studentska 16, 11000 Belgrade, Serbia; ${ }^{2}$ WasserCluster Lunz, Dr. Carl Kupelwieser \\ Promenade 5, A-3293 Lunz am See, Austria \\ *Corresponding author: dunjalkc@gmail.com
}

\begin{abstract}
Zooplankton in temporary waters produces resting stages to survive recurrent dry periods. Branchiopod crustaceans (i.e., cladocerans, large branchiopods) overcome these periods in the form of resting eggs buried in the sediment. Examining the diversity in the resting egg banks allows for a more accurate estimation of biodiversity of aquatic ecosystems than looking only at the active communities. The isolation of resting eggs from the sediment may be achieved by the sugar flotation method, which usually results in higher density and diversity than untreated samples (i.e., incubated in the sediment). We tested the effect of sugar isolation and centrifugation on the hatching success of resting eggs already isolated from sediment in order to reveal any direct effects on hatching success. We used four different branchiopod species, Daphnia magna, Moina brachiata, Branchinecta orientalis, and Triops cancriformis. Although we hypothesised that osmotic stress caused by sugar and centrifuging influence the hatching success either positively (e.g., faster activation as a response to osmotic changes) or negatively (destroyed by centrifugation), we found no significant difference either in the timing or rate of hatching between centrifuged and non-centrifuged eggs. Once the eggs are exposed to light and/or oxygen availability by being removed from the sediment, the centrifugation process does not have any additional effect on their hatching. Regardless of treatment, we found a significant difference in the hatching timing in the two major groups, with large branchiopods hatching earlier than cladocerans. We found that the sugar flotation method itself does not influence the hatching fraction of branchiopod resting eggs (implying no adverse effect on their viability) and its success in enhancing hatching can be attributed to its efficiency in removing eggs from the sediment.
\end{abstract}

Key words: Egg bank; sugar flotation method; large branchiopods; Cladocera; resting eggs.

Received: November 2015. Accepted: February 2016.

\section{INTRODUCTION}

Temporary aquatic habitats include very diverse ecosystems regarding size, shape, hydroperiod and chemistry. They are widespread throughout the world, being the most numerous in arid and semi-arid climatic regions (Brendonck, 1996). Their main common characteristic is that they are periodically unfavourable for many aquatic organisms as a consequence of drought (Schwartz and Jenkins, 2000). In extreme cases, they can remain dry for several years, even decades. Additionally, oxygen depletion and extreme temperatures can also develop at certain periods of the year (Brendonck and De Meester, 2003). During drought, sediment is exposed to strong solar radiation and high temperatures (Dumont and Negrea, 2002). Since this environment is highly unfavourable for many aquatic organisms, permanent residents possess specific life cycle adaptations, like reduced length of life and resting stages resistant to drying out.

Branchiopods (fairy shrimps, tadpole shrimps, clam shrimps and water fleas) are frequent members of temporary aquatic communities. Accordingly, their resting eggs are resistant to a wide range of environmental conditions (e.g., high insolation, extreme temperatures) (Brendonck and De Meester, 2003; Brock et al., 2003; Havel and Shurin, 2004; Radzikowski, 2013). This group developed bet-hedging strategy as a response to the unpredictable environment. As only a fraction of the resting eggs stored in the egg bank hatches during one inundation, this protects the local populations from extinction in case of abortive hatching (Hildrew, 1985; Brendonck, 1996; Simovich and Hathaway, 1997; Pinceel et al., 2013; Wang and Chou, 2015) and lessens population inbreeding by spreading generations over several years (Rogers, 2014, 2015). Dormant egg banks are not only important for bethedging, but they also contribute considerably to the temporal and spatial variation in active community composition (Brendonck and De Meester, 2003). Finally, dormant egg banks capture the total species set of habitats well (by being a footprint of all seasonally different active communities), which makes them an appropriate tool for biodiversity assessment (Vandekerkhove et al., 2005b). These latter features make egg banks important not only for temporary, but also for all permanent waterbodies.

In general, egg hatching is triggered by a combination 
of several environmental factors that most probably reflect the current quality of the habitat for growth and reproduction. The most important factors are osmotic pressure, oxygen, temperature and light exposure, but their significance varies between climatic regions (Brendonck, 1996; Brendonck and De Meester, 2003). For example, it was suggested that in the temperate zone, the most important triggers are temperature and photoperiod (Vandekerkhove et al., 2005a). Brown and Carpelan (1971) suggested that in arid regions, osmotic pressure (as indicator of salinity) and oxygen could be considered as the most important factors for hatching triggers, while in temperate regions, temperature and oxygen levels could be more indicative to inhabitants of temporary ponds.

As the dormant eggs are stored in the sediment, this makes them generally difficult to obtain and use in applied studies. Brine solution can be used to increase the number of floating eggs in a diluted sediment sample and facilitate their separation (Rogers, 2014). The sugar flotation method, introduced to accelerate and enhance the isolation success of dormant invertebrate eggs, was first applied on marine zooplankton (Onbé, 1978), and later modified by Marcus (1984; 1990). Onbé (1978) tested the success of egg separation through centrifuging on one cladoceran and one copepod species and found that centrifugation caused fast and effective separation of the eggs from the sediment. $\mathrm{He}$ also reported that centrifuging does not influence egg viability of these two marine species. Additionally, it was reported that sonication does not affect egg viability either (Marcus, 1984; De Stasio, 1989). However, in all these reports, it was not described in detail under which conditions untreated (control) eggs were incubated and there is only an indication that this method had no direct effect on hatching success of zooplankton eggs. In Vandekerkhove et al. (2004), the sugar flotation method was explicitly tested for the first time. In this study, the hatching of dormant eggs was compared between treatments with and without isolation with the sugar flotation. Isolation increased the overall hatching success and lowered activation time (the time needed for the emergence of hatchlings). In a similar study, hatching rates were also found to be significantly higher when the sugar flotation method was applied in the case of cladocerans and ostracods, while the overall number of anostracan hatchlings was higher in untreated samples (Liefferink et al., 2014). The latter two studies indicate that there can be pronounced differences between the hatching successes of zooplankton groups related to the applied incubation method. However, it remains unclear how the sugar flotation method itself affects individual zooplankton species as resulting eggs were always compared to unisolated eggs, i.e. eggs incubated with sediment.

The effect of centrifugation in sugar solution, as described in the sugar flotation method (Onbé, 1978; Mar- cus, 1990) was never explicitly tested on individual freshwater species and the hatching rates of treated and untreated eggs separated a priori from the sediment was never compared. Hence, it remains unclear, whether the sugar flotation method has a direct influence on the hatching success of crustacean zooplankton resting eggs (e.g., increasing the rate through osmotic stress or by reducing viability through centrifugation) or if it acts only indirectly through enhancing the isolation from the sediment. In this study, we present a comparison of hatching rate and hatching timing with and without applying the sugar flotation method on previously isolated eggs.

\section{METHODS}

We chose four branchiopod species for the experiments, representing their two main groups of temporary waters, cladocerans and large branchiopods. We used three widely distributed branchiopod species, the notostracan Triops cancriformis (Bosc 1801), and among cladocerans, the large-bodied Daphnia magna Straus, 1820 , along with another smaller sized temporary water species, Moina brachiata Baird, 1850. The anostracan Branchinecta orientalis G. O. Sars, 1903 is frequently found in soda pans of the Carpathian Basin (Horváth et al., 2013), and these four species occasionally co-occur in the egg banks of the soda pans (Horváth, unpublished data). We collected sediment from soda pans of the National Park Neusiedler See-Seewinkel (Austria) that are known to host these species in their egg bank in large numbers: Östliche Fuchslochlacke, for D. magna and T. cancriformis eggs; Lange Lacke, for $M$. brachiata eggs; and Oberer Stinkersee for B. orientalis eggs.

Material was stored in the dark at $4^{\circ} \mathrm{C}$ for a year. The sediment was sonicated for $30 \mathrm{~s}$ and sieved through a 250 $\mu \mathrm{m}$ mesh to isolate the eggs. We separated intact and healthy-looking eggs from the material retained in the sieve under a stereo microscope. Half of the separated eggs (treated group) was put into tubes containing sugar solution (1 kg of sucrose dissolved in $1 \mathrm{~L}$ of distilled water) and centrifuged at $3000 \mathrm{r} \mathrm{min}^{-1}$ for $3 \mathrm{~min}$ in accordance with the Onbé-Marcus sugar flotation method (Onbé, 1978; Marcus, 1990). After centrifuging, eggs were rinsed with distilled water through a sieve $(30 \mu \mathrm{m}$ mesh size) to remove the sugar residues and incubated for hatching. The second group (untreated group) was immediately incubated for hatching after removal from the sieved sediment. We put 20 eggs/ephippia of B. orientalis, T. cancriformis, D. magna or $M$. brachiata into the experimental vials (in case of D. magna, 40 eggs per vial, since each ephippium contains two eggs). This was replicated three times per treatment.

One hundred $\mathrm{mL}$ of artificial soda water $\left(\mathrm{NaHCO}_{3}\right.$ dissolved in distilled water with a concentration of $0.4 \mathrm{~g} \mathrm{~L}^{-1}$ ) of a conductivity of $500 \mu \mathrm{S} \mathrm{cm}^{-1}$ (Boros et al., 2014) was 
added to each hatching vial. Vials were placed in a walkin chamber with light set for $16 \mathrm{~h} \mathrm{per}$ day and constant temperature of $18^{\circ} \mathrm{C}$, conditions considered optimal for hatching cladocerans (Vandekerkhove et al., 2005a). The experiment ran for two weeks. We checked the vials daily for emerging juveniles, which were removed. The number of hatchlings per vial (i.e., hatching rates) and the day of hatching (hatching timing) for each individual were recorded.

For testing the treatment effect on hatching rates, we performed an independent two-group t-test for each of the species. Normal distribution of hatching rates was tested with Shapiro-Wilk tests within each treatment group per species. In case of normality, homogeneity of variances was also tested with an $\mathrm{F}$ test. Homogeneous variances were found in D. magna, M. brachiata, B. orientalis, while variances were non-homogeneous in $T$. cancriformis (here we used the Welch approximation to the degrees of freedom).

Two-way mixed model ANOVAs were performed to test for the differences in the hatching timing among the treatments (fixed), correcting for the replicates (random factor) in all tested species. The effect of random factor was never significant $(\mathrm{P}>0.05)$. To test for taxonomic group related differences in hatching timing, we used a mixed model ANOVA with taxonomic group (cladocerans and large branchiopods) as the fixed, and treatment and species as random factors. Analyses were performed with the statistical software R ( R Development Core Team, 2009).

\section{RESULTS}

\section{Hatching timing}

We found no significant differences in hatching timing between treated and untreated eggs. Daphnia magna hatched on day 6 both in treated (mean \pm SE: $6.11 \pm 0.27$; means reported in the text are calculated for previously obtained means of the replicates) and untreated (6.17 \pm 0.64$)$ samples $\left(\mathrm{F}_{(1,38)}=22.01 ; \mathrm{P}=0.13\right.$; Fig. 1), while Moina brachiata hatched on day 5 both in treated $(5.15 \pm 0.78)$ and untreated $(5.33 \pm 1.05)$ samples $\left(\mathrm{F}_{(1,21)}=2.45 ; \mathrm{P}=0.36\right.$; Fig. 1).
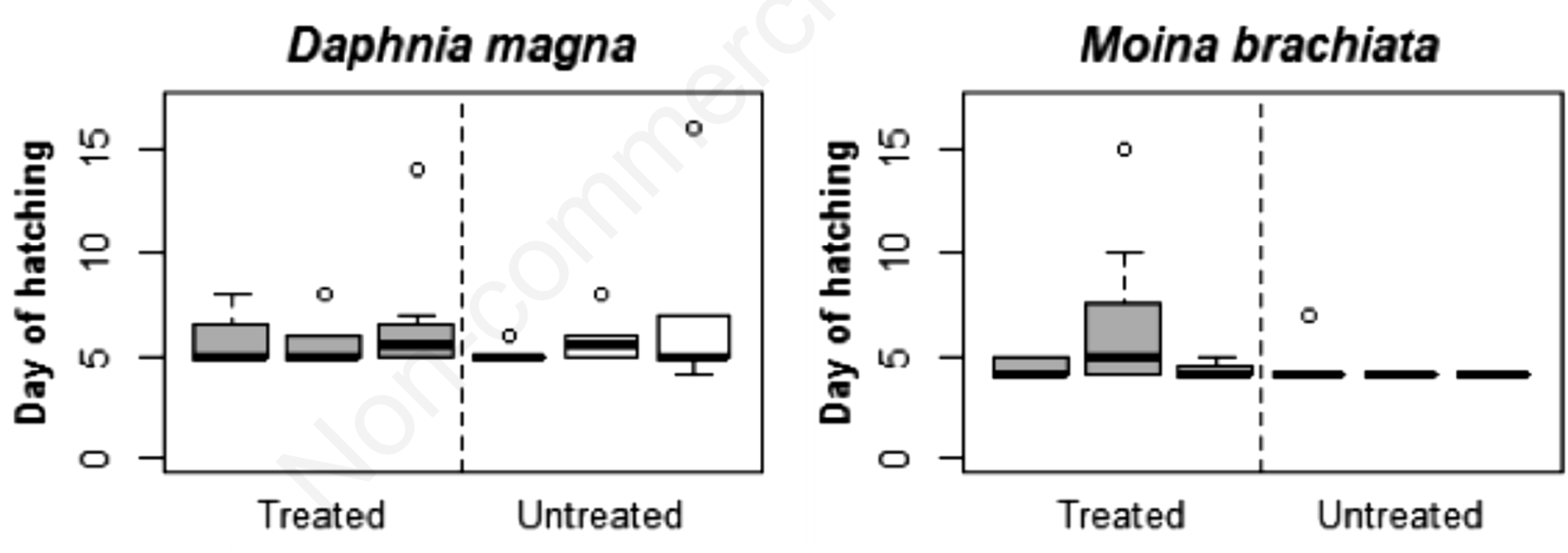

Branchinecta orientalis
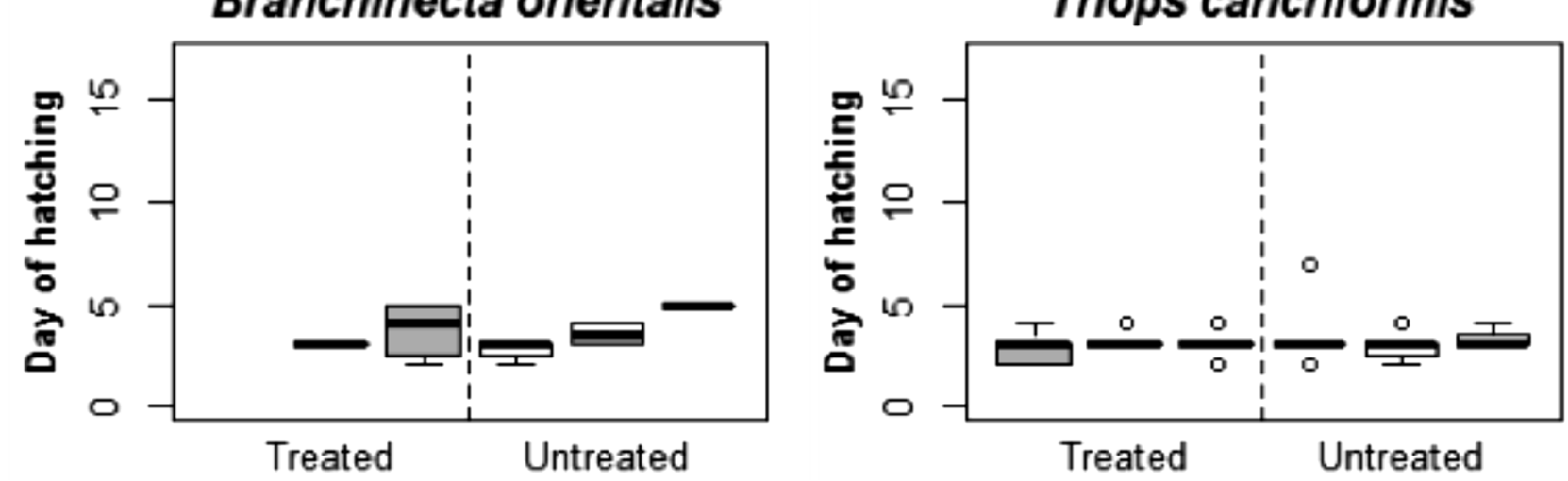

Fig. 1. Hatching timing (day of hatching) in individuals of Daphnia magna $\left(\mathrm{F}_{(1,38)}=22.01 ; \mathrm{P}=0.13\right)$, Moina brachiata $\left(\mathrm{F}_{(1,21)}=2.45\right.$; $\mathrm{P}=0.36)$, Branchinecta orientalis $\left(\mathrm{F}_{(1,7)}=131.4 ; \mathrm{P}=0.06\right)$, and Triops cancriformis $\left(\mathrm{F}_{(1,51)}=0.27 ; \mathrm{P}=0.69\right)$ for treated and untreated eggs. 
In $D$. magna, most ( $>95 \%$ ) hatchlings emerged between days 4-8 of the experiment, while $M$. brachiata $(100 \%)$ hatched between days 4-7. Branchinecta orientalis hatched between day 3 and 4 in treated $(3.37 \pm 0.37)$ and untreated (3.72 \pm 0.68$)$ samples $\left(\mathrm{F}_{(1,7)}=131.4 ; \mathrm{P}=0.06\right.$; Fig. 1). Eggs of Triops cancriformis hatched on day 3 on average both in the treated $(2.96 \pm 0.14)$ and untreated $(3.17 \pm 0.15)$ samples

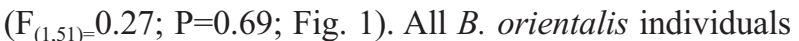
hatched between the $2^{\text {nd }}$ and $5^{\text {th }}$ day of the experiment, while $T$. cancriformis mostly ( $>98 \%$ ) hatched between the $2^{\text {nd }}$ and $4^{\text {th }}$ day.

Cladocerans generally hatched later than large branchiopods. Mean hatching (regardless of treatment) in cladocerans was day $5.65 \pm 0.29$, while in large branchiopods it was two days less $(3.14 \pm 0.10)$. This difference was also significant in the ANOVA (fixed factor of taxonomic group: $\left.\mathrm{F}_{(1,2)}=22.79, \mathrm{P}=0.04\right)$. In addition, the first cladoceran hatchling emerged on day 4 , while the first large branchiopod nauplius only appeared on day 2 .
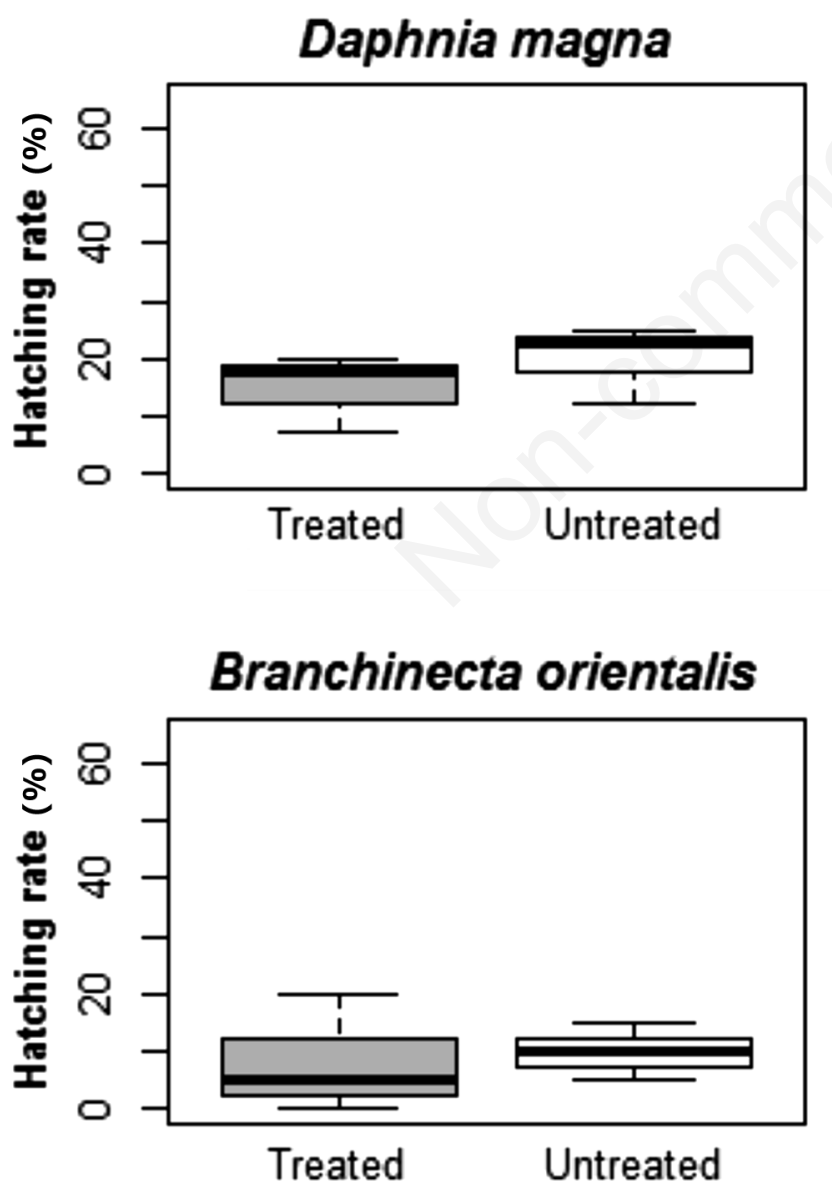

\section{Hatching rates}

There was no significant difference in hatching rates between the treated and untreated eggs for any of the studied species. Average hatching rates in D. magna were slightly higher in untreated samples $(20 \pm 3.82 \mathrm{vs}$ $15 \pm 3.82 \%)$, but this difference was not significant ( $t$-test, $\mathrm{t}=-0.93 ; \mathrm{P}=0.41 ;$ Fig. 2$)$. In $M$. brachiata, the hatching rates were somewhat higher in treated samples (but again not significant, $t$-test, $\mathrm{t}=1.15 ; \mathrm{P}=0.32$; Fig. 2 ), with mean values $25 \pm 5.77 \%$ in treated and $16.67 \pm 4.41 \%$ in untreated samples.

The anostracan $B$. orientalis showed a similar, but not significant tendency as D. magna, with a mean hatching rate of $8.33 \pm 6.00 \%$ in the treated samples and $10 \pm 2.89 \%$ in untreated samples ( $t$-test, $\mathrm{t}=-0.25 ; \mathrm{P}=0.82 ;$ Fig. 2$). T$. cancriformis showed overall higher hatching rates than the other species and a tendency similar to M. brachiata. In the treated samples, $T$. cancriformis mean hatching rate
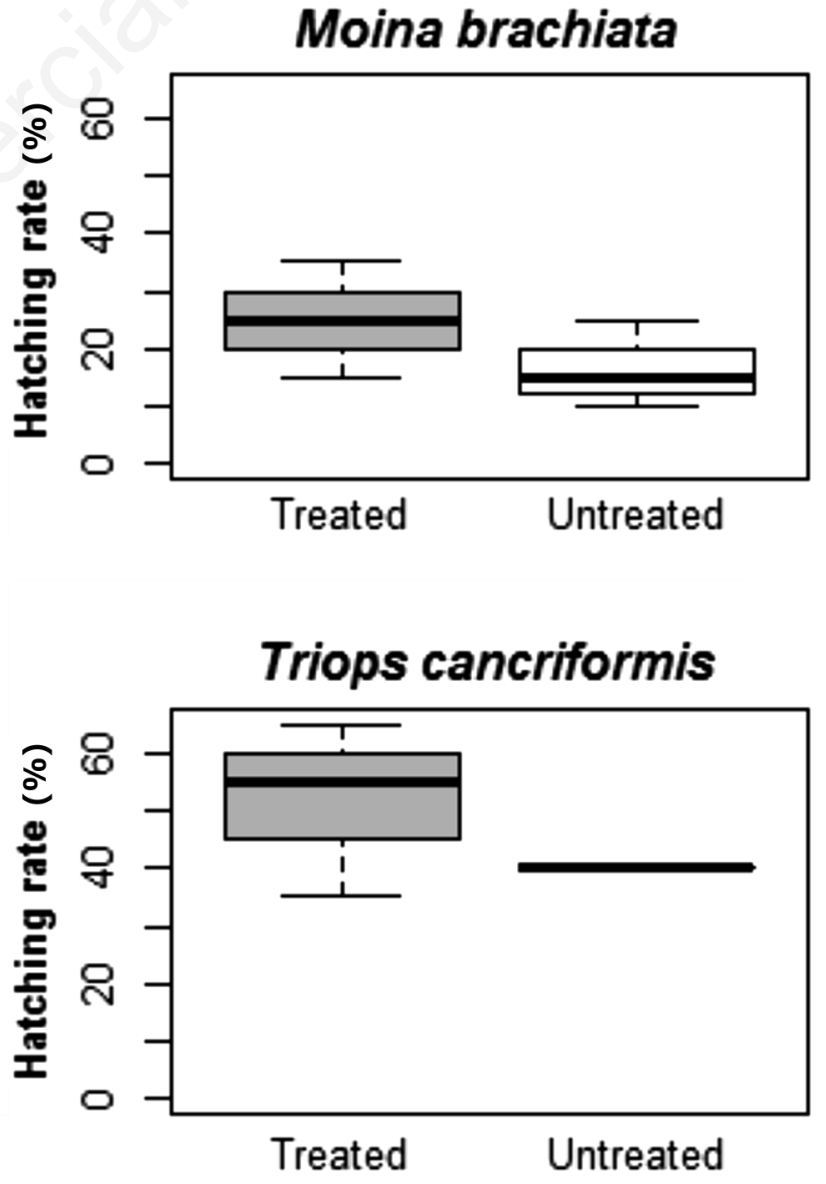

Fig. 2. Hatching rates of Daphnia magna $(\mathrm{t}=-0.93 ; \mathrm{df}=4, \mathrm{P}=0.41)$, Moina brachiata $(\mathrm{t}=1.15 ; \mathrm{d}=4$, $\mathrm{P}=0.32)$, Branchinecta orientalis $(\mathrm{t}=-0.25 ; \mathrm{df}=4, \mathrm{P}=0.82)$, and Triops cancriformis $(\mathrm{t}=1.32 ; \mathrm{df}=2, \mathrm{P}=0.32)$ for treated and untreated eggs. 
was $51.67 \pm 8.82 \%$, while it was $40 \pm 0.00 \%$ in the untreated samples ( $t$-test, $\mathrm{t}=1.32 ; \mathrm{P}=0.32$; Fig. 2).

\section{DISCUSSION}

Vandekerkhove et al. (2004) previously reported that hatching rates were higher and hatching was more rapid using the sugar flotation method as opposed to the direct incubation of eggs without isolating them from the sediment. They argued that the isolation procedure itself may have contributed to the results (i.e., direct effect), but changes in other environmental factors, such as exposure to light or oxygen availability after isolation could have also had indirect effects. Our study demonstrated that the efficiency of the sugar flotation method is attributable to environmental factors.

Many studies report the significance of light exposure for hatching of various zooplankton taxa (reviewed in Brendonck, 1996), like the anostracan Streptocephalus macrurus Daday, 1908 (Mitchell, 1990), the notostracan Triops longicaudatus (LeConte, 1846) (Scott and Grigarick, 1979) and the cladoceran Daphnia sp. (Schwartz and Hebert, 1987). Oxygen availability also proved to be important for the hatching success of various zooplankton groups (Brown and Carpelan, 1971; Lutz et al., 1992; Roman et al., 1993). These records are consistent with claims that hatching success is strongly reduced when anostracan (Brendonck et al., 1998; Shardin et al., 2015) and notostracan (Scott and Grigarick, 1979) eggs are buried in the sediment. It is also suggested that light-triggered hatching is an adaptive mechanism contributing to bet-hedging. As it only induces the hatching of a fraction of eggs, by having little or no effect on the eggs covered by sediment, this limits egg bank depletion in case of abortive hatching (Brendonck et al., 1998).

Our results show that osmotic pressure caused by sugar and centrifuging does not have significant influence on branchiopod hatching timing and rates. Our results suggest that once the eggs had been removed from the sediment, they were exposed to better light and (very likely) oxygen conditions, that were more important factors in the regulation of hatching than the isolation method itself.

Hatching was synchronised in the treated and untreated samples within the same species. Schwartz and Hebert (1987) demonstrated that, at a temperature same as in our experiment $\left(18^{\circ} \mathrm{C}\right)$, Daphnia eggs started to hatch five days after inundation. Our results for the day of hatching in Branchinecta orientalis (mean: $\sim 3$ days, earliest hatchlings emerging on day 2) were consistent with those obtained by Atashbar et al. (2014), who tested the hatching success of three anostracan species, including B. orientalis, at different salinities and temperatures. Atashbar et al. (2014) also found that anostracans start to hatch two days after inundation at lower salinity and temperature.

We found that cladocerans hatched later than large branchiopods. This difference in the hatching timing can be related to the embryonic development within the egg as anostracans and notostracans emerge from the eggs in larval stage (as nauplii), while cladocerans appear as miniature adults (Dumont and Negrea, 2002). Additionally, once the eggs are activated in large branchiopods, there is no further division of the cells, but the existing cells of an embryo rapidly differentiate into a nauplius, which is different in cladocerans, where both cell division and differentiation take place (Dumont and Negrea, 2002).

Regardless of treatment effect, there was a large difference among hatching rates between species. Triops cancriformis had the highest hatching rate (mean for treated and untreated samples together was $45.83 \%$ ), followed by Moina brachiata (mean 20.83\%) and Daphnia magna (mean 17.5\%), and the lowest observed hatching rate was in B. orientalis (mean 9.17\%). In a study with several species of genus Branchinecta, the hatching rates were even lower than in our case, especially in soil samples $(0-4 \%)$, while hatching rates in eggs recovered from waterbirds were higher, but still relatively low $(0-14 \%)$ (Rogers, 2014). In their review, Brendonck and De Meester (2003) similarly found that anostracans frequently have hatching rates below $20 \%$. Moreover, wide intraspecific differences in hatching success were found previously even within the same populations of $D$. magna (De Meester and De Jager, 1993) and Daphnia pulicaria (Cáceres and Tessier, 2003).

We suggest that the hatching rate results in our study, ranging from 0 to $65 \%$, were not influenced by the separation solution, but were an effect of dormancy itself. Briski et al. (2013) reached the same conclusion after obtaining similar hatching rates in their experiment where they compared two separation methods, sugar flotation and colloidal silica sol Ludox HS 40. The generally low hatching rates could be the consequence of bet-hedging strategy. Due to the unpredictable nature of temporary waters, deciding whether to stay dormant or to hatch, represents an important decision as abortive hatching may lead to egg depletion (Brendonck, 1996). Although there are many suggestions how to enhance the hatching success of invertebrate resting eggs (Brendonck, 1996), its drivers are still not fully understood, and results may vary considerably between populations and within populations of the same species. Moreover, differences seem to exist even between eggs from the same brood (Hildrew, 1985; Brendonck, 1996; Simovich and Hathaway, 1997; Pinceel et al., 2013; Wang and Chou, 2015).

\section{CONCLUSIONS}

We found that osmotic pressure caused by sugar solution, centrifugation and subsequent placement in much more diluted medium (as part of the Onbé-Marcus sugar flotation method) cannot be considered as a hatching trig- 
ger for branchiopod eggs, and neither can it cause any significant changes in the hatching success of the examined branchiopod species. Our results showed that the contribution of the sugar flotation to a higher number of hatchlings and faster emergence (Vandekerkhove et al., 2004) is due to the effect of removing the sediment covering the eggs, and compared to hand-picked isolation, it does not increase hatching rates or speed. On the other hand, our results also prove sugar flotation as a non-invasive method so it can be used also when the number of eggs in a sample is limited. Therefore, application of the method is advisable for studying branchiopod species, since it facilitates egg tracing within the sediment and contributes to the exposition of eggs to light, which seem to be its major advantages.

\section{ACKNOWLEDGMENTS}

The study visit of D. L. at WasserCluster Lunz was supported by the scholarship of the Scholarship Foundation of the Republic of Austria for Undergraduates, Graduates and Postgraduates. D. L. is also a scholarship holder at the Serbian Ministry of Education, Science and Technological Development. Authors are grateful to D. Christopher Rogers and an anonymous reviewer for valuable suggestions which vastly improved the manuscript.

\section{REFERENCES}

Atashbar B, Agh N, Van Strappen G, Mertens J, Beladjal L, 2014. Combined effect of temperature and salinity on hatching characteristics of three fairy shrimp species (Crustacea: Anostraca) J. Limnol. 73:574-583.

Boros E, Horváth Zs, Wolfram G, Vörös L, 2014. Salinity and ionic composition of the shallow astatic soda pans in the Carpathian Basin. Ann. Limnol.-Int. J. Lim. 50:59-69.

Brendonck L, 1996. Diapause, quiescence, hatching requirements: what we can learn from large freshwater branchiopods (Crustacea: Branchiopoda: Anostraca, Notostraca, Conchostraca). Hydrobiologia 320:85-97.

Brendonck L, De Meester L, 2003. Egg banks in freshwater zooplankton: evolutionary and ecological archives in the sediment. In: E. Van Donk, M. Boersma and P. Spaak (eds.), Recent developments in fundamental and applied plankton research. Hydrobiologia 491:65-84.

Brendonck L, Riddoch BJ, Van de Weghe V, Van Dooren T, 1998. The maintenance of egg banks in very short lived pools - a case study with anostracans (Branchiopoda). Arch. Hydrobiol. 52:141-161.

Briski E, Bailey SA, MacIsaac HJ, 2013. Separation strategies for invertebrate dormant stages contained in sediment. Aquatic Biol. 18:209-215.

Brock MA, Nielsen DL, Shiel RJ, Green JD, Langey JD, 2003. Drought and aquatic community resilience: the role of eggs and seeds in sediments of temporary wetlands. Freshwater Biol. 48:1207-1218.

Brown LR, Carpelan LH, 1971. Egg hatching and life history of a fairy shrimp Branchinecta mackini Dexter (Crustacea:
Anostraca) in a Mohave desert playa (Rabbit Dry Lake). Ecology 52:41-54.

Cáceres CE, Tessier AJ, 2003. How long to rest: the ecology of optimal dormancy and environmental constraint. Ecology 84:1189-1198.

De Meester L, De Jager H, 1993. Hatching of Daphnia sexual eggs. I. Intraspecific differences in the hatching responses of D. magna eggs. Freshwater Biol. 30:219-226.

De Stasio BJ, 1989. The seed bank of a freshwater crustacean: Copepodology for the plant ecologist. Ecology 70:1377-1389.

Dumont HJ, Negrea SV, 2002. Introduction to the class Branchiopoda. Guides to the identification of the microinvertebrates of the continental waters of the world. Backhuys Publishers, Leiden: 398 pp.

Havel JE, Shurin JB, 2004. Mechanisms, effects, and scales of dispersal in freshwater zooplankton. Limnol. Oceanogr. 49:1229-1238.

Hildrew AG, 1985. A quantitative study of the life history of a fairy shrimp (Branchiopoda: Anostraca) in relation to the temporary nature of its habitat, a Kenyan rain pool. J. Anim. Ecol. 54:99-110.

Horváth Zs, Vad CsF, Vörös L, Boros E, 2013. Distribution and conservation status of fairy shrimps (Crustacea, Anostraca) in the astatic soda pans of the Carpathian basin: the role of local and spatial factors. J. Limnol. 72:103-116.

Liefferink SL, Tate RB, Van Vuren JHJ, Ferreira M, Malherbe $\mathrm{W}, 2014$. A comparison of methods for incubating zooplankton diapausing eggs from sediment of endorheic pans in the Free State, South Africa. Afr. J. Aquat. Sci. 2014:1-7.

Lutz RV, Marcus NH, Chanton JP, 1992. Effects of low oxygen concentrations on the hatching and viability of eggs of marine calanoid copepods. Mar. Biol. 114:241-247.

Marcus NH, 1984. Recruitment of copepod nauplii into the plankton: importance of diapause eggs and benthic processes. Mar. Ecol.-Prog. Ser. 15:47-54.

Marcus NH, 1990. Calanoid copepod, cladoceran, and rotifer eggs in sea-bottom sediments of northern Californian coastal waters: identification, occurrence and hatching. Mar. Biol. 105:413-418.

Mitchell SA, 1990. Factors affecting the hatching of Streptocephalus macrourus Daday (Crustacea; Eubranchiopoda) eggs. Hydrobiologia 194:13-22.

Onbé T, 1978. Sugar flotation method for the sorting the resting eggs of marine cladocerans and copepods from seabottom sediment. Bull. Jpn. Soc. Sci. Fish. 44:1411.

Pinceel T, Vanschoenwinkel B, Uten J, Brendonck L (2013). Mechanistic and evolutionary aspects of light-induced dormancy termination in a temporary pond crustacean. Freshw. Sci. 32:517-524.

Radzikowski J, 2013. Resistance of dormant stages of planktonic invertebrates to adverse environmental conditions. J. Plankton Res. 35:707-723.

R Development Core Team, 2009. R: A language and environment for statistical computing. Vienna, Austria.

Rogers DC, 2014. Larger hatching fractions in avian dispersed anostracan eggs (Branchiopoda). J. Crustacean Biol. 34:135143.

Rogers DC, 2015. A conceptual model for anostracan biogeography. J. Crustacean Biol. 35:686-699.

Roman MR, Gauzens AL, Rhinehart WK, White JR, 1993. Ef- 
fects of low oxygen waters on Chesapeake Bay zooplankton. Limnol. Oceanogr. 38:1603-1614.

Schwartz SS, Hebert PDN, 1987. Methods for the activation of the resting eggs of Daphnia. Freshwater Biol. 17:373-379.

Schwartz SS, Jenkins DG, 2000. Temporary aquatic habitats: constraints and opportunities. Aquat. Ecol. 34:3-8.

Scott S, Grigarick A, 1979. Laboratory studies of factors affecting egg hatch of Triops longicaudatus (Leconte) (Notostraca:Triopsidae). Hydrobiologia 63:145-152.

Shardin NV, Anufriieva EV, Amat F, Eremin OY, 2015. Dormant stages of crustaceans as a mechanism of propagation in the extreme and unpredictable environment in the Crimean hypersaline lakes. Chin. J. Oceanol. Limn. 33:1362-1367.

Simovich MA, Hathaway SA, 1997. Diversifies bet-hedging as a reproductive strategy of some ephemeral pool anostracans (Branchiopoda). J. Crustacean Biol. 17:38-44.
Vandekerkhove J, Declerck S, Brendonck L, Conde-Porcuna JM, Jeppesen E, De Meester L, 2005a. Hatching of cladoceran resting eggs: temperature and photoperiod. Freshwater Biol. 50:96-104.

Vandekerkhove J, Declerck S, Brendonck L, Conde-Porcuna JM, Jeppesen E, Johansson LS, De Meester L, 2005b. Uncovering hidden species: hatching diapausing eggs for the analysis of cladoceran species richness. Methods 3:399-407.

Vandekerkhove J, Niessen B, Declerck S, Jeppesen E, CondePorcuna JM, Brendonck L, De Meester L, 2004. Hatching rate and hatching success with and without isolation of zooplankton resting stages. Hydrobiologia 526:235-241.

Wang CC, Chou LS, 2015. Terminating dormancy: hatching phenology of sympatric large branchiopods in Siangtian pond, a temporary wetland in Taiwan. J. Crustacean Biol. 35:301-308 